\title{
A Survey of Knowledge of Sexually Transmitted Infections among Patients at a Public Hospital in Pulau Pinang, Malaysia
}

\author{
Mudassir Anwar a Syed A. Syed Sulaiman ${ }^{b}$ Tahir M. Khan b, c

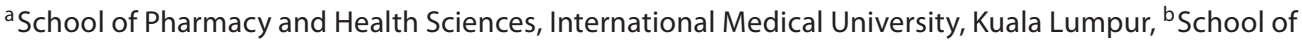 \\ Pharmaceutical Sciences, Universiti Sains Malaysia, and 'School of Pharmacy, Island College of Technology, \\ Balik Pulau, Malaysia
}

\section{Key Words}

Knowledge $\cdot$ Sexually transmitted infections $\cdot$ Patients

\begin{abstract}
Objective: The aim of this study was to assess the patients' knowledge and awareness of sexually transmitted infections (STIs). Subjects and Methods: A face-to-face interview was conducted among the patients visiting the Venereal Diseases Outpatient Department of the General Hospital of Pulau Pinang (Malaysia). A 19-item questionnaire was used. A total of 116 patients participated in the study and 107 patients had valid responses. The reliability and internal consistency of the questionnaire tool was estimated on the basis of Cronbach's alpha $(=0.81)$. The Statistical Package for Social Sciences (SPSS 13.0 ${ }^{\circledR}$ ) was used for data analysis. Student's t test and analysis of variance were used to analyse the knowledge differences among the groups. Results: Of the 107 patients, 82 (76.6\%) were diagnosed with syphilis; AIDS was the most commonly known STI among the patients. Of the 107 patients, 35 were sexually active and of these $23(65.7 \%)$ had more than 1 sexual partner. The most popular source of knowledge was newspapers (51 patients, 47.7\%), with hospitals (3 patients, 2.8\%) being the least popular one. Overall mean score on knowledge questions was 12.21 out of the maximum of 33 points. Knowledge about causative organisms, risk groups, transmission, symptoms, prevention and
\end{abstract}

\section{KARGER}

Fax +4161306 1234

E-Mail karger@karger.ch

www.karger.com
(C) 2010 S. Karger AG, Basel

$1011-7571 / 10 / 0194-0312 \$ 26.00 / 0$

Accessible online at:

www.karger.com/mpp treatment of STIs was inadequate. The knowledge level was significantly related to gender $(p=0.03)$, religion $(p=0.005)$, educational level $(p=0.000)$, marital status $(p=0.000)$ and income level $(p=0.036)$. Conclusion: This study demonstrated evidence of poor knowledge of STIs amongst the patients attending an STI service in the General Hospital of Pulau Pinang (Malaysia). Hence there is an immediate need for efforts towards improving patient knowledge of STIs.

Copyright $\odot 2010$ S. Karger AG, Base

\section{Introduction}

Sexually transmitted infections (STIs) have long been recognised as a major public health dilemma because of their high incidence and contribution to morbidity and mortality [1]. Though many STIs are easy to treat, delay in seeking appropriate care can result in increased severity and complications [2]. Historically, knowledge about STIs has been very low even in communities where there is high prevalence of STIs. In some cases, STIs may be viewed as unavoidable or may even be viewed as an 'initiation into adulthood' [3]. There may be lack of concern about STIs because they may be viewed as easily curable [3].

Knowledge is an important prevention factor for STIs [4]. It has been suggested that knowledge about STI trans- 
mission might influence sexual behaviour [5]. A study in the Netherlands provided evidence that patients with low educational backgrounds often delayed seeking professional help longer than those with high educational backgrounds, and also that those patients living in rural areas were more likely to delay than those living in the urban areas [6]. A study in the USA found that low socioeconomic status was associated with delay in treatment [7]. Furthermore, the knowledge, attitude and sexual practices relating to STIs have an association with delay in seeking care for STIs. Studies in South Africa found that misconceptions regarding the cause of STIs are responsible for delay in seeking help and treatment of STIs [8, 9]. Equally, embarrassment and/or social stigma often resulted in prolonged interval before seeking cure $[6,7]$. Women are more at risk due to low level of knowledge of STIs. Studies in Kenya and South Africa have shown that women who continued to have sex while having STI symptoms were more likely to delay than other women $[1,9]$.

In Malaysia, the Ministry of Health has noted a downward trend in the number of reported STI cases. For example, the number of reported syphilis cases has decreased from 1,965 in 2000 to 900 in 2005, while that of gonorrhoea declined from 1,356 cases in 2000 to 537 in 2005 [10]. This downward trend may be due to the underreporting of cases, because of the stigma attached to these infections and the increasing ease of, and accessibility to, treatment at private clinics [10]. So far no findings were available that provide evidence of knowledge, attitudes and perceptions of STI patients toward STIs. Therefore the aim of this study was to assess patients' awareness of STIs and to compare the knowledge level on STIs across different socio-demographic groups.

\section{Subjects and Methods}

A face-to-face interview was conducted among the patients visiting the Venereal Diseases Outpatient Department of the General Hospital of Pulau Pinang (Malaysia). Pulau Pinang is one of Malaysia's 13 states and is situated in the north of Peninsular Malaysia. It is a multicultural state comprising of Malay (42.5\%), Chinese (46.5\%), Indian (10.6\%) and others (0.4\%), with an estimated population of 1.5 million [11].

\section{Participants}

Participants of this study were patients over 18 years of age attending the clinic for STI checkups between July 15 and August 30, 2007. All the participants were diagnosed with an STI by the clinicians from the Venereal Diseases Outpatient Department of the General Hospital of Pulau Pinang. A total of 121 patients were approached but only 116 of them agreed to participate in the study. Due to the sensitive nature of the study, especially in the context of Malaysia, an Asian country with traditional values, the sample for study could not be selected randomly. Owing to ethical considerations, all the patients aged 18 years and over attending the Outpatient Department of Venereal Diseases for STIs checkups, who were diagnosed with STIs during the study period, were offered the chance to participate in the study. Those who were interested in the study were referred to the interview room, where the interviewer explained the details of the study.

\section{Study Tool}

For data collection, a 19-item questionnaire was developed in English. The questionnaire was then translated into Bahasa Melayu (the national language of Malaysia). Of these 19 items, the first 7 questions addressed socio-demographic information. One item each was on the knowledge about different types of STIs, the symptoms of STIs, preventive measures for STIs, the risk groups, complications, route of transmission and causative organisms. In addition to these, 3 items were about sexual practices, knowledge source and perception about STIs. Each knowledge question included multiple statements and the respondents were allowed to choose more than one.

The face and content validity was performed by the professionals at the disciplines of Social and Administrative Pharmacy Department at University Sains Malaysia and by the Department of Biostatistics at the General Hospital of Pulau Pinang. The reliability scale was applied to all the variables comprising the knowledge domain (i.e. knowledge about the different STIs, symptoms, awareness about causes/prevention and diagnosis and therapy). The reliability and internal consistency of the tool were estimated on the basis of Cronbach's alpha $(=0.81)$. Though all the respondents could speak Bahasa Melayu, the level of competency was unknown and difficult to analyse. Therefore, to avoid complications all the interviews were conducted in the native language of the respondents by researchers with an excellent proficiency level in the Malay, Indian and Chinese languages.

\section{Data Collection}

This study employed face-to-face interviews using a semistructured questionnaire. Ethical approval was obtained from the social and behavioural research ethics committee, University Sains Malaysia and the director of the General Hospital of Pulau Pinang. All the questionnaires were kept anonymous and the confidentiality of the information provided was assured to the respondents.

\section{Knowledge of Sexually Transmitted Infections}

Knowledge of STIs was assessed using the number of correct STI names, symptoms and transmission routes reported by participants. Each correct response under a question equalled one score. The maximum score that could be obtained was 33. Participants were evaluated according to the points they received from knowledge questions: $0-10$ points = low level; $11-21=$ moderate level; 22-33 = high level of knowledge.

\section{Data Analysis}

For data analysis, the Statistical Package for Social Sciences $\left(\right.$ SPSS13.0 ${ }^{\circledR}$ ) was used. Descriptive statistics were used to demon- 
strate the results. Some of the questions had multiple choices to choose from; therefore the sum total of percentages was not always $100 \%$. Student's t test and analysis of variance (ANOVA) were used to analyse the knowledge and practice differences among the groups.

\section{Results}

Of the 116 participants, 107 (92.2\%) had valid responses and the remaining 9 (7.8\%) survey forms were rejected because of the incomplete information. Of the $107 \mathrm{pa}-$ tients, 57 (53.3\%) were male and 50 (46.7\%) female. Other socio-demographic factors are given in table 1. Only 35 (32.7\%) disclosed that they had experienced sexual intercourse and of these 23 (65.7\%) had more than 1 sexual partner. Details about the first age of intercourse and number of sexual partners are shown in table 2. Of the 107 patients, $82(76.6 \%)$ were diagnosed with syphilis, followed by genital warts in $11(10.3 \%)$, gonorrhoea in 10 (9.3\%), HIV/AIDS in $3(2.8 \%)$ and herpes in $1(0.9 \%)$.

Thirty-two participants $(30.0 \%)$ disclosed that they had no knowledge about any type of STIs. The majority (59; 55.1\%) claimed that they had knowledge of AIDS. Detailed responses about knowledge of different types of STIs are illustrated in figure 1.

\section{Knowledge about Causative Organisms, Risk Groups and Transmission of STIs}

The majority $(68 ; 64.5 \%)$ were unaware of the causative organisms for STIs; however, those aware had ranked viruses as one of the most commonly known causative organisms, followed by bacteria and fungi. The respondents' beliefs about the route of transmission of STIs are described in figure 2 .

\section{Knowledge about Symptoms of STIs}

In order to evaluate knowledge about symptoms of STIs, 8 symptoms were given as options. The most commonly known symptom of STIs by the patients was itching on genital area with abdominal pain as the least commonly known symptom. Detailed responses about recognition of symptoms of STIs are presented in table 3.

\section{Knowledge about Diagnosis, Medications and \\ Prevention of STIs}

Diagnosis of STI was by a blood test in $52(48.6 \%)$ participants, genital examination in $19(17.8 \%)$, genital secretions in $18(16.8 \%)$ and urine test in 15 (14\%). In terms of treatment, $67(65.5 \%)$ participants were unaware of any
Table 1. Socio-demographic data of the respondents

\begin{tabular}{lc}
\hline Characteristic & $\mathrm{n}(\%)$ \\
\hline $\begin{array}{l}\text { Mean age (range) } \\
\text { Ethnic group }\end{array}$ & $38.5 \pm 14.39(18-65$ years) \\
$\quad$ Malay & $42(39.3)$ \\
Chinese & $41(38.3)$ \\
Indian & $15(14.0)$ \\
Others & $9(8.4)$ \\
Educational level & \\
No formal education & $3(2.8)$ \\
Primary & $30(28.0)$ \\
Secondary & $38(35.5)$ \\
College & $20(18.7)$ \\
University & $16(15.0)$ \\
Marital status & \\
Single & $29(27.1)$ \\
Married & $26(61.7)$ \\
Divorced & $8(7.5)$ \\
Widowed & $4(3.7)$ \\
Monthly income level (USD) & \\
Low (<285) & $25(23.4)$ \\
Middle (285-855) & $72(67.3)$ \\
High $(>855)$ & $10(9.3)$ \\
\hline
\end{tabular}

Table 2. Sexual behaviour of the respondents

\begin{tabular}{lr}
\hline Behaviour & $\mathrm{n}(\%)$ \\
\hline Sexual experience & $35(32.7)$ \\
$\quad$ Yes & $54(50.5)$ \\
No & $18(16.8)$ \\
No answer & $6(17.1)$ \\
Age at first intercourse & $16(45.7)$ \\
15-19 & $13(37.2)$ \\
$20-25$ & \\
26 and above & $12(34.3)$ \\
Number of partners & $8(22.9)$ \\
One & $15(42.8)$ \\
Two & \\
Three and above &
\end{tabular}

drugs for STIs; however, 40 (35.5\%) recommended the use of antibiotics.

Whilst exploring the respondents' beliefs towards the prevention of STIs, 50 (46.7\%) recommended avoiding sexual contact with prostitutes, other proposed strategies are given in table 4 . In a response to the question about seeking professional help, respondents preferred to consult a general practitioner. 
Fig. 1. Knowledge about various types of STIs. Multiple responses were obtained so the collective percentage was not $100 \%$.

Fig. 2. Knowledge about route of transmission.
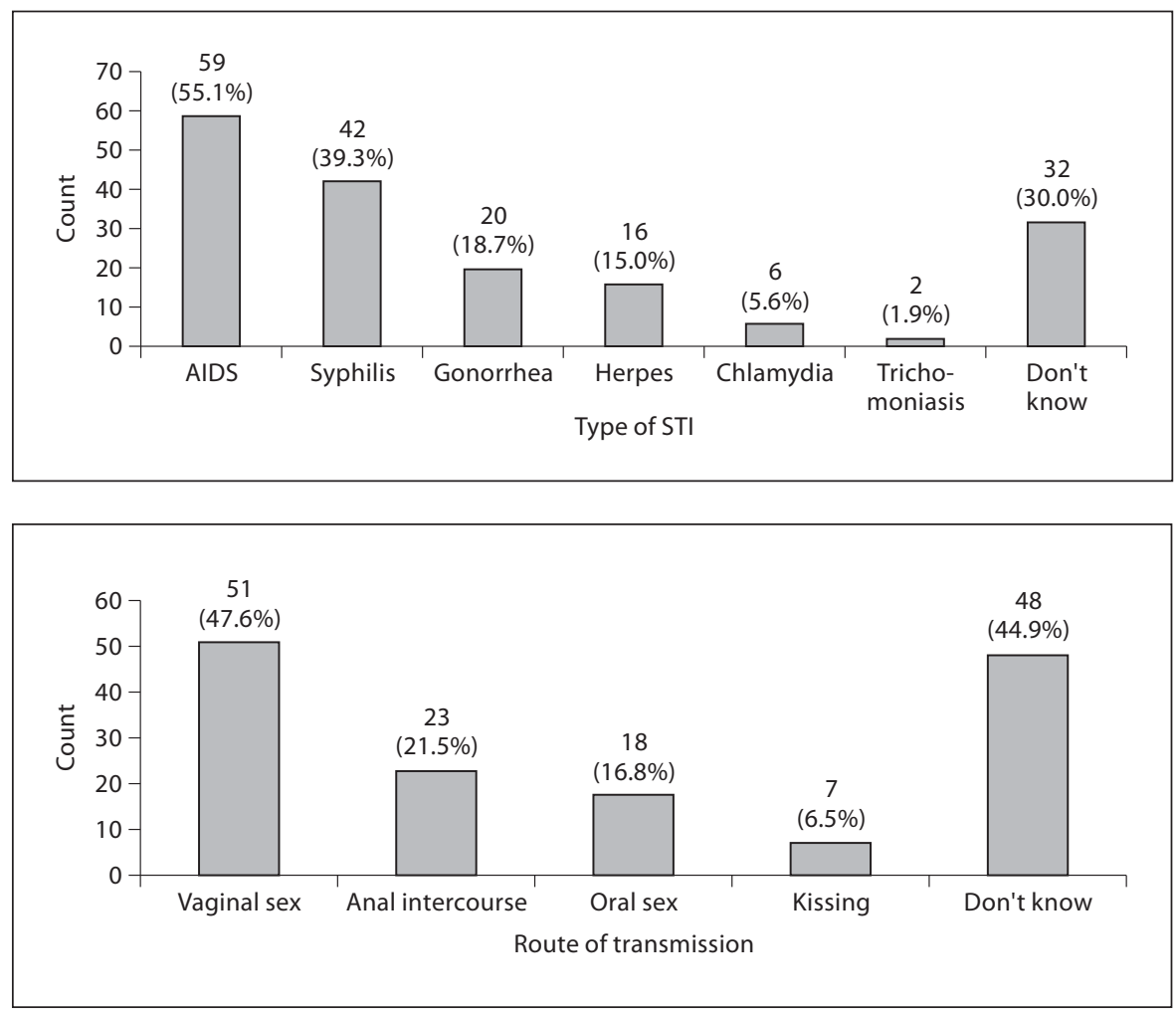

Table 3. Patients' knowledge of symptoms of STIs

\begin{tabular}{|c|c|c|c|c|c|c|c|c|}
\hline \multicolumn{9}{|l|}{ Ethnic group } \\
\hline Malay & 6 & 10 & 8 & 2 & 5 & 2 & 0 & 0 \\
\hline Chinese & 17 & 9 & 17 & 11 & 17 & 2 & 6 & 9 \\
\hline \multicolumn{9}{|l|}{ Gender } \\
\hline Male & 18 & 18 & 22 & 16 & 21 & 2 & 4 & 7 \\
\hline Female & 19 & 11 & 11 & 5 & 9 & 5 & 5 & 5 \\
\hline \multicolumn{9}{|l|}{ Age } \\
\hline $18-30$ years & 16 & 14 & 10 & 10 & 10 & 5 & 5 & 8 \\
\hline $31-40$ years & 7 & 5 & 11 & 7 & 12 & 2 & 2 & 2 \\
\hline Primary & 8 & 6 & 8 & 8 & 6 & 3 & 3 & 0 \\
\hline Secondary & 11 & 8 & 8 & 2 & 4 & 4 & 4 & 2 \\
\hline College & 7 & 4 & 6 & 4 & 7 & 0 & 0 & 5 \\
\hline University & 11 & 11 & 11 & 7 & 13 & 0 & 2 & 5 \\
\hline
\end{tabular}


Table 4. Strategies to prevent STIs

\begin{tabular}{|c|c|c|c|c|c|c|c|c|}
\hline $\begin{array}{l}\text { Demographic } \\
\text { variables }\end{array}$ & $\begin{array}{l}\text { Avoid sexual } \\
\text { intercourse } \\
(n=25)\end{array}$ & $\begin{array}{l}\text { Limit number } \\
\text { of sexual part- } \\
\text { ners }(n=21)\end{array}$ & $\begin{array}{l}\text { Use condom } \\
\text { during sex } \\
(n=42)\end{array}$ & $\begin{array}{l}\text { Use sterilized } \\
\text { syringes } \\
(\mathrm{n}=12)\end{array}$ & $\begin{array}{l}\text { Avoid sexual } \\
\text { intercourse with } \\
\text { prostitutes }(n=50)\end{array}$ & $\begin{array}{l}\text { Non-pen- } \\
\text { etrative sex } \\
(\mathrm{n}=11)\end{array}$ & $\begin{array}{l}\text { Take antibi- } \\
\text { otics prior } \\
\text { to } \operatorname{sex}(n=3)\end{array}$ & $\begin{array}{l}\text { Avoid homo- } \\
\text { sexual contact } \\
(\mathrm{n}=11)\end{array}$ \\
\hline Malay & 7 & 8 & 10 & 2 & 16 & 3 & 0 & 5 \\
\hline Chinese & 7 & 7 & 18 & 7 & 19 & 0 & 0 & 4 \\
\hline Indian & 6 & 6 & 10 & 3 & 11 & 6 & 3 & 0 \\
\hline Male & 15 & 16 & 28 & 8 & 32 & 6 & 3 & 11 \\
\hline Female & 10 & 5 & 14 & 4 & 18 & 5 & 0 & 0 \\
\hline \multicolumn{9}{|l|}{ Age } \\
\hline $18-30$ years & 13 & 10 & 19 & 5 & 21 & 5 & 0 & 2 \\
\hline $31-40$ years & 7 & 6 & 10 & 5 & 10 & 3 & 3 & 2 \\
\hline Primary & 9 & 9 & 9 & 3 & 17 & 9 & 3 & 5 \\
\hline Secondary & 7 & 0 & 6 & 0 & 6 & 0 & 0 & 2 \\
\hline College & 4 & 5 & 11 & 2 & 16 & 2 & 0 & 2 \\
\hline University & 5 & 7 & 16 & 7 & 11 & 0 & 0 & 2 \\
\hline
\end{tabular}

\section{Misconceptions}

There were also some misconceptions about STIs among the patients, as $11(10.3 \%)$ believed that 'if the symptoms disappear it means the STI is cured', which may not be true with every STI, and 63 (58.9\%) did not know. Also 30 (28\%) of the patients believed that 'STIs can only be spread when symptoms are present'. However, the majority of patients (more than 60\%) believed that STIs require medical treatment and a patient with an STI should also get his/her partner checked and treated.

\section{Source of Knowledge}

The most common source of information was newspapers and magazines (51 patients; 47.7\%), television (21; $19.6 \%)$, the internet $(9 ; 8.4 \%)$, seminars $(9 ; 8.4 \%)$, doctors (6; 5.6\%) and hospital $(3 ; 2.8 \%)$. Twenty-six $(24.3 \%)$ of the patients claimed that they do not seek information about STIs from any source.

\section{Knowledge Score and Socio-Demographic Factors}

The overall mean score on knowledge questions was 12.21 out of a maximum of 33 and, equally important, this score is towards the lower end of the score for moderate level of knowledge (11-21). Significant differences in levels of knowledge were apparent according to gender, religion, education, marital status and income level (as detailed in table 5).

\section{Discussion}

This survey was the first to assess the public knowledge of STIs in patients attending the Outpatient Department of Venereal Diseases at the General Hospital of $\mathrm{Pu}$ lau Pinang. The majority $(\mathrm{n}=40 ; 37.4 \%)$ of the respondents were from the age group 18-30 years. This finding is similar to that of Mayer-Weitz et al. [12] who in 2003 found the majority of the patients attending an STI clinic were younger than 35 years. The majority of participants had little awareness of STIs, which has been found to be an important determinant of delayed healthcareseeking behaviour [13]. Whilst evaluating the recognition of symptoms, findings revealed that $40.2 \%(n=43)$ were not aware of any symptoms of STIs, which could result in delay in seeking treatment and further complicating the condition. This finding of little awareness of STI symptoms correlates with the findings of a study by Mukisa et al. [14] in 1993 in Uganda. A surprising fact was that although $76.6 \%$ of the respondents had a confirmed diag- 
Table 5. Comparison of scores on knowledge questions according to socio-demographic factors and sexual experience (107 patients)

\begin{tabular}{|c|c|c|c|c|}
\hline & $\mathrm{n}$ & $\begin{array}{l}\text { Mean score } \\
\pm \mathrm{SD}\end{array}$ & $\begin{array}{l}\mathrm{t} \text { value/ } \\
\mathrm{F} \text { value }\end{array}$ & $\begin{array}{l}\mathrm{p} \\
\text { value }\end{array}$ \\
\hline \multicolumn{5}{|l|}{ Gender } \\
\hline Male & 57 & $14.47 \pm 8.991$ & & \\
\hline Female & 50 & $9.64 \pm 8.481$ & $2.319^{\mathrm{a}}$ & 0.003 \\
\hline \multicolumn{5}{|l|}{ Ethnic group } \\
\hline Malay & 42 & $9.45 \pm 8.505$ & & \\
\hline Chinese & 41 & $13.22 \pm 9.046$ & $1.722^{\mathrm{b}}$ & 0.167 \\
\hline Indian & 15 & $15.93 \pm 8.660$ & & \\
\hline Others & 9 & $14.33 \pm 9.244$ & & \\
\hline \multicolumn{5}{|l|}{ Religion } \\
\hline Muslim & 47 & $9.15 \pm 8.516$ & & \\
\hline Hindu & 9 & $22.33 \pm 8.395$ & & \\
\hline Christian & 14 & $16.43 \pm 8.535$ & $3.903^{\mathrm{b}}$ & 0.005 \\
\hline Buddhist & 31 & $12.71 \pm 9.143$ & & \\
\hline Others & 6 & $8.67 \pm 8.397$ & & \\
\hline \multicolumn{5}{|l|}{ Education level } \\
\hline No formal education & 3 & 0 & & \\
\hline Primary & 30 & $6.87 \pm 8.736$ & & \\
\hline Secondary & 38 & $10.63 \pm 6.510$ & $-0.56^{\mathrm{a}}$ & 0.000 \\
\hline College & 20 & $16.65 \pm 8.369$ & & \\
\hline University & 16 & $24.62 \pm 9.350$ & & \\
\hline \multicolumn{5}{|l|}{ Marital status } \\
\hline Single & 29 & $16.52 \pm 8.758$ & & \\
\hline Married & 26 & $9.35 \pm 8.397$ & $7.739^{\mathrm{b}}$ & 0.000 \\
\hline Divorced & 8 & $25.37 \pm 9.768$ & & \\
\hline Widowed & 4 & $2.00 \pm 0$ & & \\
\hline \multicolumn{5}{|c|}{ Monthly income level (USD) } \\
\hline Low $(<285)$ & 25 & $10.41 \pm 8.789$ & & \\
\hline Middle (285-855) & 72 & $12.00 \pm 8.292$ & $3.427^{\mathrm{a}}$ & 0.036 \\
\hline High $(>855)$ & 10 & $33.00 \pm 9.350$ & & \\
\hline \multicolumn{5}{|l|}{ Sexual experience } \\
\hline Yes & 35 & $16.43 \pm 8.479$ & & \\
\hline No & 54 & $12.48 \pm 8.710$ & -1.678 & 0.156 \\
\hline
\end{tabular}

${ }^{\mathrm{a}}$ t value (Student's t test); ${ }^{\mathrm{b}} \mathrm{F}$ value (ANOVA). $\mathrm{p}<0.05$ was considered significant.

nosis of syphilis, AIDS was the most commonly recognised STI. Similar are the findings of Farr et al. [15], who in 1990 who found that the majority of the patients (90\%) answered the questions about AIDS correctly. There is considerable other research on adolescents or the general public in different parts of the world that has also revealed the same [16-19]. For prevention of STIs, the most commonly recommended strategy was to avoid sexual contact with prostitutes, followed by the use of condoms $39.2 \%(\mathrm{n}=42)$. Use of condoms as one of the most effective measures to prevent STIs has been reported by certain other researchers from different countries in their studies on the awareness of STIs [18-20]. This study has not evaluated the respondents contact level with prostitutes; however, $21.5 \%(\mathrm{n}=23)$ disclosed sexual relations with more than 1 partner. In terms of treatment, about one third recommended the use of antibiotics to treat STIs, and nearly all were willing to seek the treatment from a general practitioner.

There was almost equal participation in the study from all educational groups, except the uneducated, who made up only $2.8 \%(\mathrm{n}=3)$. The fact that the sample included respondents from almost all educational groups showed that people from various groups suffer from STIs. There is no previous study in Malaysia in regard to these findings, providing evidence that the focus of knowledge and prevalence of STIs is not limited to the already identified high-risk groups.

One of the important roles that hospitals could play is to improve the awareness of different health-related issues. In this study, hospital was found to be the least popular source of information, which suggests a need to improve in this area in order to increase patients' awareness and knowledge of STIs.

The overall mean score of 12.21 on knowledge questions shows that patients have a moderate level of knowledge. As expected, gender, education level and income level were important factors to determine the knowledge level, with male gender, higher education and high socioeconomic status related to high knowledge level. Knowledge was also significantly related to religion, with Hindus being more knowledgeable than their counterparts. An interesting finding was that patients who claimed to be sexually active had better knowledge as compared to those who claimed to be sexually inactive. It suggests that a higher knowledge level alone cannot always ensure responsible behaviour, as indicated previously. This type of finding has been confirmed by Shapiro et al. [21], who in 1999 indicated that greater knowledge may be associated with high-risk behaviour.

This study has some limitations. Firstly, all the patients who showed willingness to participate in the survey were recruited, regardless of whether they were newly registered or follow-ups. It may be that newly registered patients were not aware of the symptoms, preventive measures, diagnosis and therapy, whereas follow-up patients might have a better knowledge of STIs. This could lead to the differences in knowledge level. As the scope of this study was merely to compare the knowledge level among different socio-demographic groups so the data on whether the respondent was a newly registered case or was on follow-up, was not gathered. Furthermore, to 
maintain the privacy and confidentiality of all the gathered information, patients' records were not accessed. Secondly, the section evaluating the help-seeking behaviour did not consider the patient's attitudes toward the use of traditional or herbal medicines, which can be a possible issue to be considered in future studies.

\section{Conclusion}

This study provided evidence of an inadequate level of knowledge of STIs among STI patients. Efforts towards increasing STI knowledge are broadly needed in Malaysia, and specifically for people who are attending STIrelated clinics.

\section{References}

1 Dallabetta GA, Field ML, Laga M, Islam QM: Control of Sexually Transmitted Diseases Section I: Management of STD Programs. http://www.fhi.org/en/hivaids/pub/guide/ stdhandbook/chap1.htm (accessed March $17,2008)$.

-2 Voeten HA, O’hara HB, Kusimba J, Otido JM, Ndinya-Achola JO, Bwayo JJ, Varkevisser CM, Habbema JD: Gender differences in health care-seeking behaviour for sexually transmitted diseases: a population-based study in Nairobi, Kenya. Sex Transm Dis 2004;31:265-272.

3 HIV and STDs: A collaborative effort between NY State Department of Health AIDS Institute, Office of the Medical Director and the Johns Hopkins University School of Medicine, Division of Infectious Diseases. www.hivguidelines.org (accessed July 3, 2007).

4 Kraft P: Sexual knowledge among Norwegian adolescents. J Adolesc Health 1993;16: 3-21.

5 Lahai-Momoh JC, Ross MW: HIV/AIDS prevention-related social skills and knowledge among adolescents in Sierra Leone, West Africa. Afr J Reprod Health 1997;1:37-44.

6 Leenaars PEM, Rombouts R, Kok G: Seeking medical care for a sexually transmitted disease: determinants of delay behaviour. Psychol Health 1993;8:17-32.

7 Fortenberry JD: Health care seeking behaviours related to sexually transmitted diseases among adolescents. Am J Public Health 1997;87:417-420.
-8 Meyer-Weitz A, Reddy P, Van den Borne WH, Kok G, Pietersen J: The determinants of health care seeking behaviour of adolescents attending STD clinics in South Africa. J Adolesc Health 2000;23:741-752.

$\checkmark 9$ Meyer-Weitz A, Reddy P, Van-den-Borne WH, Kok G, Pietersen J: Health care seeking behaviour of patients with sexually transmitted diseases: determinants of delay behaviour. Patient Educ Couns 2000;41:263274.

10 Chua Soi Lek: Ministry of Health Malaysia, at the 14th IUSTI (International Union on Sexually Transmitted Infections). AP 2006 Conference, Kuala Lumpur, 2006.

11 Socio-Economic and Environmental Research Institute (SERI): Penang Statistics, quarter 2, 2007, p 3. http://www2.seri.com. my/Penang\%20Statistics/2007/Q2-AprilJune-2007-1.pdf (accessed March 20, 2008).

12 Meyer-Weitz A, Reddy P, Van den Borne WH, Kok G, Pietersen J: Determinants of multi-partner behaviour of male patients with sexually transmitted diseases in South Africa: implications for interventions. Int J Mens Health 2003;2:149-162.

13 Hien TT, Ziersch A, Hart G: Healthcareseeking behaviours for sexually transmitted infections among women attending the $\mathrm{Na}$ tional Institute of Dermatology and Venereology in Vietnam. Sex Trans Infect 2007;83: 406-410.

14 Mukisa E, Rubagiza J: Awareness of STDs among Ugandan national STD clinic patients. Int Conf AIDS 1993;9:837.
15 Farr G, Magruder C, Foldesy R, Greenup R, Staab R: Knowledge and awareness of AIDS among patients at a sexually transmitted disease clinic. Int Conf AIDS 1990;6:261

16 Lemeki M, Passey M, Setel P: Ethnographic results of a community STD study in the Eastern Highlands Province. PNG Med J 1996;39:239-242.

17 Abera Z: Knowledge, attitude, and behavior (KAB) on HIV/AIDS/STDs among workers in the informal sector in Addis Ababa. Ethiop J Health Dev 2003;17:53-61.

18 Temin MJ, Okonofua FE, Omorodion FO, Renne EP, Coplan P, Kris H, Kaufman J: Perceptions of sexual behavior and knowledge about STDs among young adolescents in Benin City, Nigeria. Int Fam Plan Perspect 1999;25:186-195.

19 Gokengin D, Yamazhan T, Ozkay D, Aytug S, Ertem E, Arda B, Serter D: Sexual knowledge, attitudes and risk behaviours of students in Turkey. J Sch Health 2003;73:258263.

20 Selak S, Juric V, Hren D, Juric M: What do young people from Mostar, Bosnia and Herzegovina know about contraception and sexual health? Croat Med J 2004;45:44-49.

21 Shapiro J, Radescki S, Charchian AS, et al: Sexual behavior and AIDS-related knowledge among community college students in Orange County, California. J Community Health 1999;24:29-43. 